\title{
A RESPEITO DA LITERATURA TRIVIAL
}

\author{
Marta Morais da Costa ${ }^{*}$
}

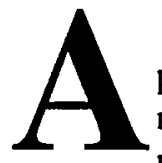

presença da literatura na escola sempre desperta interrogações a respeito da melhor metodologia para formar o leitor, bem como provoca nos professores-leitores o desafio de efetuar uma seleção de obras objetivando a leitura eficaz e significativa de seus alunos. Com frequeência, os agentes responsáveis por essa indicação se vêem confrontados no momento de escolher livros com seu gosto pessoal, com a pressão das editoras, com a velada censura institucional e familiar, com o preço dos livros e, finalmente, com a teoria e as informações recentes a respeito do fato literário e de sua natureza.

Em batalhas silenciosas, pressupostas mas pouco divulgadas, os professores vivem a angústia de atender aos pré-requisitos de uma indicação de leitura e de obter com isso o êxito de conquistar leitores. Esse é, aliás, o objetivo mais perseguido por qualquer agente de leitura: tornar o contato com o livro um momento de prazer específico e de conhecimento especial que somente a literatura proporciona.

O embate entre as possíveis escolhas compõe uma face penosa do trabalho docente. Defrontam-se neste espaço informações provenientes das 
mais diversas fontes e que irão construir um horizonte de expectativas, ${ }^{1}$ fundamental para a opção finalmente realizada. A confluência dos valores construídos pela obra ao longo do tempo e nos mais diferentes tipos de leitores pavimenta a via de acesso ao livro escolhido. A apreciação já realizada, seja no campo do prazer dos leitores, seja na avaliação dos críticos e historiadores, age substancialmente no momento da indicação de livros para a leitura estudantil.

Sob a força de atração - especialmente destes dois pólos, o do prazer e os dos valores culturais - ziguezagueia a seleção de obras para estudo e leitura. Origina-se dessa bipolaridade a hesitação que acomete os professores no momento de tratar da literatura trivial. ${ }^{2}$ lido?

Qual o critério capaz de distinguir com acerto a escolha do livro a ser

Adotada a ótica do educando, pode-se apostar todas as fichas em que o interesse particular, a capacidade relativa de compreender narrativas complexas e o modelo narrativo redundante resultarão na escolha, com margem mínima de erro, da literatura trivial, por sua extensão, linguagem e tema. Em outra perspectiva e comandado pela justificativa mas eles gostam!, o professor subordina o momento da leitura ao enquadramento do repetido, do já-sabido e do fácil. Adotando o comportamento de diagnose, estudando-se os sintomas, somando a eles esquemas já conhecidos de definições e características e uma boa dose de normatizações, é possível receitar uma obra já esperada, padronizada, imune a riscos e ruídos na leitura. Por isso, a escolha recai na trivialização, com seu modo de apresentação não problemática, que não extrapola os aspectos particulares e miúdos da vida cotidiana. Essa opção pelo trivial aposta na mais valia do gosto, ${ }^{3}$ nascida da exploração cultural de muitos em privilégio de outros poucos.

Esta exploração cultural consistirá na reedição de velhas fórmulas de sucesso: o fantástico, o folclore, a novela de aventuras, as histórias policiais e de ficção científica. A aceitação desse funcionamento conforme $e^{4}$ dificulta o acesso a outras formas e fórmulas de menor êxito junto ao público e torna intransponível o abismo entre essa literatura de conformação e a de ruptura.

Cabe ressaltar que o atendimento à pressão exercida pela literatura trivial nas escolhas do professor não se manifesta apenas pela força econômica do mercado editorial. A pressão resulta também, e principalmente, pela eleição de

I ISER, Wolfgang. O ato da leitura: por uma teoria do efeito estético. Trad. de Joahannes Krestschmer. São Paulo: Editora 34, 1996. p. 12.

2 KOTHE, Flávio. A narrativa trivial. Brasília: Editora da UnB, 1994.

.3 MAGNANI, Maria do Rosário. Leitura, lite rutura e escola: sobre a formação do gosto. Sĩo Paulo: Martins Fontes, 1989. p. 57.

4 Ibid., p. 58. 
formas literárias expressando padrões culturais históricos, resultantes de redes de relação estabelecidas entre a ideologia e os diferentes textos culturais. Cada época é dominada por um sistema de gêneros ${ }^{5}$ e a literatura, instrumento de aprendizagem escolar, reflete as dominâncias desse sistema.

Em seu nascedouro, a literatura, assentada nos bancos escolares, recebeu o batismo da concepção platônica e horaciana, que prega a ligação do útil ao agradável e a função educativa da palavra artística. Este viés formador incutiu marcas indeléveis na leitura escolar. Até mesmo o atendimento ao dito "interesse" dos educandos ignora a profundidade e a complexidade desses mesmos interesses, limitando-se a um entendimento emergencial e paliativo. Quando um aluno declara seu interesse por textos de suspense, por exemplo, a receita do professor é imediata: o romance policial. Na verdade, o que este leitor particular está pedindo é a satisfação maior da leitura, isto é, o texto que prende e amarra o leitor a seu processo de enunciação. Deseja-se o suspense para criarum vínculo inalienável com a leitura, para amarrar-se (em gíria e etimologia) ao livro a fim de juntos, leitor e texto, descobrirem o ignorado mas intuído. $O$ leitor quer, ainda que virtualmente, ultrapassar as barreiras de sua (in)significância humana, projetando-se na possibilidade de desafiar o desconhecido e o não sabido. $O$ suspense coloca em xeque a impotência humana mas também a oportunidade de superá-la. Anseia-se por ele como forma de descobrir os limites e sua superação. $O$ suspense é a encruzilhada da natureza humana: abrem-se a partir dele os caminhos da ultrapassagem e do sem-retorno.

Nessa linha de reflexão, é possível estabelecer uma justificativa psíquica importante para a adoção de narrativas que incluem o suspense como elemento de composição textual.

Ainda refletindo a respeito dos porquês da opção por narrativas triviais, é possível encontrar já nos anos 50 uma razão compensatória para essa leitura. Fraser Bond atribuía a "frustrações inevitáveis", do público a necessidade de consumir textos oriundos da indústria cultural e do acervo da denominada cultura de massa. Entre essas frustrações podiam ser detectadas a do impulso motor, a do impulso lúdico, a do impulso de poder e a do impulso de amor.

Na primeira se encontram as pessoas "sem capacidade de iniciativa", buscando nos relatos um antídoto para essa espécie de "paralisia motora", configurado em ação e violência contínuas ou na forma civilizada do esporte e da concorrência contínua.

5 ZILBERMAN, Regina; CADEMARTORI, Ligia. Literatura infantil: autoritarismo e emancipaçĩ̄o. São Paulo: Ática, 1982. p. 2.

6 BOND, Fraser. Introdução ao jornalismo. Apud SODRÉ, Muniz. A verdade seduzida. 2. ed. Rio de Janeiro: Francisco Alves, 1988. p. 82-83. 
Já a frustração do impulso lúdico corresponde à busca constante da brincadeira e do riso como forma de atenuar as tensões e as responsabilidades do ofício de viver. A exigência cada vez mais intensa de comicidade em textos culturais se explica também como uma compensação às crises profundas da sociedade neste final de século.

Para reverter as frustrações do impulso de poder, buscam os leitores "a mitificação dos triunfos alheios". 7 A abundância de heróis e salvadores, de modelos de vencedores - seja por méritos próprios seja por força da esperteza ou das circunstâncias - povoa os produtos culturais, atraindo sobremaneira o público leitor.

$\mathrm{Na}$ retomada do caminho do só pelo amor vale a vida, mesmo que nele estejam plantadas sementes de violência, a produção cultural que atende às frustrações do impulso de amor reinstala a moda romântica, não mais um platonismo amoroso mas um sentimento piegas e extremado.

Eu acrescentaria às quatro categorias de "frustrações inevitáveis" de Bond a frustração do impulso ético. Numa sociedade comandada pelo relativismo dos valores éticos, quando não por sua inexistência, textos que prevejam, ainda que minimamente, saídas honrosas e/ou gloriosas podem compensar esse vazio. Estariam incluídos na categoria os textos de linhagem esotérica ou ecológica e os de intenções claramente moralizadoras e comportamentais.

A ligar esses modelos diversos de compensação psíquica está a sua forma "tautológica, repetitiva, mágica"8 - cujo padrão de exigências mínimas mantém - e por vezes aumenta - a distância com a cultura elevada, "crítica e produtora de verdades transcendentes". 9

Essa distinção nos permite dimensionar por outro ângulo a questão da seleção de textos. Se a adoção de livros da literatura de massa proporciona o atendimento a frustrações de ordens diversas, sob a perspectiva da formação do leitor, e em especial do leitor crítico, novos argumentos podem ser apresentados.

A incapacidade reiterada do sistema de ensino de instrumentalizar seus alunos nas atividades básicas de leitura e escrita produziu ao longo das últimas décadas uma multidão de alfabetizados secundários, ${ }^{10}$ incapazes de um desempenho eficiente na recepção e produção de textos simples. Para esses leitores as dificuldades de acesso à literatura complexa assumem proporções desmedidas. A primeira reside, sem dúvida, na intelecção mínima do vocabulário e da

7 BOND, (1). cit., p. 83.

8 Ibid., p. 87.

9) Ibid., p. 87

I0 ENZENSBERGER, Hans Magnus. Mediocridade e loucura. São Paulo: Ática, 1995. p. 41 . 
estrutura da frase. A imaginação é impulsionada não pelo nível simbólico do texto, mas pela incapacidade de relacionar a palavra/frase lida a qualquer referente. No vazio do significado passa a atuar a fantasia do leitor, procurando preencher a palavra/frase com algum sentido. Esse mecanismo de pura adivinhação cria choques permanentes entre os significados, desarticulando-os, criando ordens não coesivas e incoerentes. O produto dessa turbulência dos e nos sentidos manifesta-se em tipos de reação diversos: abandono do texto, produção de uma interpretação caótica, estabelecimento de relações ilógicas entre textos, sentimento de impotência, frustração e desgosto na leitura. Se o leitor estiver sob a pressão de uma avaliação ou obrigado à leitura, cresce enormemente a angústia de estabelecer nexos possibilitadores da compreensão.

Ante este quadro de caos e/ou abandono, como proceder ao selecionar textos? É possível conciliar a formação do leitor crítico com o atendimento às deficiências de leitura, acentuadas por um ensino ineficaz? Esse é o nó mais difícilmente desatável da leitura escolar.

Pensemos que uma história de leitura se constrói ao longo do tempo, das experiências vividas $\mathrm{e}$ da leitura praticada. A sociedade brasileira, representada nas suas mais diversas instituições - a escola, a família, os meios de comunicação, a Igreja, entre outras - tem compreendido a leitura como um atributo escolar e, posteriormente à educação formal, como uma responsabilidade exclusiva do sujeito leitor. Considerando, porém, a pressão exercida pela comunidade e pelos meios de comunicação no que respeita à reprodução e divulgação de textos para a massa, podemos entender como o leitor se torna uma presa fácil das armadilhas do consumo, pois, como afirma Muniz Sodré: "A literatura de massa não tem nenhum suporte escolar ou acadêmico: seus estímulos de produção e consumo partem do jogo econômico da oferta e procura, isto é, do próprio mercado." $\mathrm{E}$ nele, as qualidades textuais são descritas mais por adjetivos relacionados a efeitos emotivos, como "emocionante", "envolvente", "eletrizante", "inesquecível", que pela atenção à forma, ao desmascaramento da ideologia dominante, aos atributos estéticos. O conteúdo domina a feitura desses produtos e se configura numa combinação de "elementos policiais, com aventuras, com sentimento ou sexo, com terror, com sagas familiares [numa] estrutura do texto folhetinesco", 12 a saber, um vocabulário básico, sintaxe elementar, personagens sem profundidade, tendentes ao tipo e ao clichê, ações intensas e ritmo alucinante.

II SODRÉ, Muniz. Best-seller: a literatura de mercado. São Paulo: Ática. 1985. p. 6.

12 Hid., p. 55. 
Umberto Eco aponta alguns aspectos relativos à associação, na literatura trivial, de prazer, consumo e sucesso que merecem ser ressaltados:

1. Todo artista aspira a ser lido. [...] 2. Todo texto aspira a proporcionar prazer em sua leitura adequada. [...] 3. Parece que alguns autores de narrativa pura se desinteressam pelo estilo, aspirando a um leitor que apenas aprecie as histórias que se contam. [...] 4. Toda obra se propōe pelo menos dois tipos de leitor: o primeiro é vítima designada pelas próprias estratégias enunciativas, o segundo é o leitor crítico que ri do modo pelo qual foi levado a ser vítima designada.

Posicionando-se radicalmente contra a importância estética da produção trivial, Flávio Kothe define assim sua estrutura e valor moral:

[...] a narrativa trivial [...] reitera sempre um esquema ético à base de estereótipos, sem jamais realmente aprofundar o que ai se considera bem e mal. Através de milhares de variantes de superfícies, dá surpreendentes voltas para acabar chegando ao mesmo lugar. O receptor quer receber a confirmação dos seus preconceitos e pré-juízos. Vegeta, ao invés de pensar. Recebe essa doutrinação como se fosse para diversāo. Cultiva a passividade, desiste de pensar. Sob a identificação com heróis positivos idealizados, cria o mergulho dionisíaco no inconsciente coletivo sem levá-lo à conscientização e superação. ${ }^{14}$

Essa diatribe contra a banalidade desconsidera, contudo, a necessidade de conviverem o dionisíaco e o apolíneo, o inconsciente coletivo e o individual. Não exerceria a trivialização uma importante função catártica, em qualquer fase da vida? Há momentos em que o leitor deseja simplesmente o aconchego da redundância, o ócio do já-conhecido, o mergulho nas águas da mesmice. Minutos de alicnação completam as horas da "conscientização e da superação". Como para um atleta, o relaxamento faz parte indissociável de qualquer treina-

1.3 ECO, Uinberto. Sobre os espelhos e outros ensaios. 2. ed. Trad. de Beatriz Borges. Rio de Janeiro: Nova Fronteira, 1989. p. 100-101.

14 KOTHE, op. cit., p. 10-11. 
mento. Como também é verdade que nenhum atleta se sai bem se continuar relaxando infindavelmente.

O crítico norte-americano James Atlas se refere ao público da literatura trivial pressionado pela evolução gráfico-cultural-econômica do século: “[...] o público de literatura começou a mudar. Como o crítico literário inglês $\mathrm{Q}$. D. Leavis observou em Fiction and the reading public, a leitura para a literatura séria começou a desaparecer no começo do século 20 por causa da expansão do jornalismo popular e da publicação do que mais tarde seria chamado de romances de armazém em edições baratas [...] um golpe na literatura séria." ${ }^{15}$ Mas outras características da literatura do nosso século contribuíram para o afastamento do leitor: a descontinuidade e fragmentação, a literatura como meio de registrar estados da alma e a revolução na linguagem colocaram "a literatura [...] além do alcance do leitor comum - em outras palavras, [ela tornou-se] propriedade de uma elite". ${ }^{16}$ Ao final dessa evolução é possível encontrar entre os próprios escritores o desprazer na leitura desses textos sérios. Segundo John Berryman em suas Dream songs, "a literatura me aborrece, especialmente a grande litcratura". "A mim também", completa James Atlas.

Sem desmerecer a literatura de elite, mas também sem preferir os romances de almazém, a busca do leitor passa a ser pela união entre fiç̧̃̃o e história, segundo Atlas. Atendem A esta união romances como os de Balzac, Conrad, Foster, Saul, Bellow, Philip Roth e John Updike, entre outros. Fica assim sugcrido um caminho de leitura, enriquecedor para o leitor em formação.

Talvez seja esta uma linha de raciocínio a ser seguida na scleção de textos: reconhecer a atmosfera de encantamento que um bom contador de histórias pode criar, observar a força comovedora e imantada de um texto acessível. Por força comovedora entendo a do texto que sensibiliza sem ser piegas, emociona por meios poéticos e não clicherizados, abala o leitor passivo e acomodado, sem precipitá-lo na escuridão do incompreensível e do hermético. Isto significa que é possível programar a formação do leitor, prevendo um repertório cuja progressão objetive sempre a leitura de textos consistentes e de qualidade.

A literatura trivial, por suas características intrínsecas de redundância, pobreza estilística e intenções consumistas dispensa a mediação da escola e do professor. Ela sobrevive longe dos bancos escolares, de vez que procura atender plenamente as expectativas de seus leitores e o nível de interpretação possível

15 ATLAS, James. A missão prolixa de escrever sobre a alma. O Estudo de S. Paulo, p. D-2, 30 mar. 1997.

16 llitl. 
em sua leitura. Como afirma Alfredo Bosi a respeito dos componentes da chamada indústria cultural:

Os processos psicológicos envolvidos nesses programas são, em geral, os de apelo imediato: sentimentalismo, agressividade, erotismo, medo, fetichismo, curiosidade. [...] Há uma dosagem de realismo e conservadorismo que, ao mesmo tempo, excita o desejo de ver, mexe com as emoções primárias e as aplaca no happy end. ${ }^{17}$

Verifica-se, portanto, uma variedade de argumentos a favor e contra a literatura trivial. Cabe perguntar agora que lugar ocupariam, num projeto de leitura literária, as narrativas e a poesia triviais. Há que se ter em mente qual "a linha determinada pela filosofia de valores própria do projeto político-social que os utilizar". ${ }^{8}$

Se os valores estiverem localizados numa aprendizagem do mecanismo de leitura, concebido enquanto exercício de língua e interpretação - mediado por lichas, resumos, questionários, provas... - a literatura banalizada cumprirá uma função indiscutível. $O$ estudante, além de capacitar-se a atender os comandos do professor, irá se sentir recompensado por desempenhar-se satisfatoriamente enquanto leitor passivo. Será uma espécie de participante de um lauto banquete cultural onde serão servidos exclusivamente os insossos e gordurosos hambúrgueres, regados a refrigerantes de última geração, cada vez mais semeIhantes a remédios e laxantes. A literatura trivial, encarada sob esta perspectiva, enquadra-se numa concepção de empreendimento bancário em que a quantidade será o parâmetro da aprendizagem: ler muito para escrever melhor é o lema dessa ótica utilitarista.

Uma segunda filosofia de valores, que podemos designar culturalista e epistemológica, planifica uma aproximação comparativa dos textos culturais em que a literatura trivial entra como um componente indispensável. Esse procedimento comparativo e intertextual visa compreender a constituição das obras, a relação entre autor, texto e leitor e os protocolos de leitura, a semiótica das diferentes linguagens. Neste caso, esse produto cultural conservador é devidamente localizado

17 BOSI, Alfredo. Dialética da colonização. São Paulo: Companhia das Letras, 1992. p. 321 .

18 lbid.., p. 322. 
no universo dos textos e aí ocupa um lugar insubstituível. Pode ser compreendido e descrito, mantendo, porém, uma relação estática com os demais textos.

Uma terceira posição, que poderia ser denominada cidadã ou democrática, visa uma "introdução larga ao conhecimento do Homem e da Sociedade, uma ocasião constante de desenvolvimento da própria linguagem, como expressão subjetiva e comunicação intersubjetiva; enfim, um despertar para o que de mais humano e belo tem produzido a imaginação plástica, musical e poética no Brasil ou fora do Brasil". ${ }^{19}$ Esse é um projeto educador, por excelência. Nele são convergentes as correntes eruditas, as criadoras personalizadas, ${ }^{20}$ as da indústria cultural e as correntes de expressão popular. Nessa simbiose, a literatura trivial é encarada sob a perspectiva de sua integração e posterior superação. $\mathrm{O}$ conhecimento e a compreensão das diferenças possibilitam não apenas um olhar sobre o presente, mas também um projeto para o futuro.

Nesse terceiro projeto, o professor passa a ocupar um lugar imprescindivel e de absoluta pertinência, pois the caberá a função de "levar o homem iletrado não à letra em si (letra morta ou letal) mas à consciência de si, do outro, da natureza". 21

Em qualquer um dos três projetos a escolha de exemplares da literatura banalizada e conservadora poderá encontrar abrigo. Nasce da opção por uma ou outra das três filosofias de valores o papel a ser desempenhado pelo professor, pelo leitor e pelo sistema escolar. A tensão que descrevíamos no início pode, assim, desaparecer, transformada na assunção de uma posição política e cultural mais definida e da qual resultarão todos os atos posteriores. Agora é só decidir: os caminhos estão abertos.

\section{RESUMO}

Este texto aborda os procedimentos metodológicos possiveis na escolha da literatura trivial para a utilização na escola. Medita a respeito da constituição textual dessa literatura e condiciona a leitura desses textos redundantes e conservadores a três filosofias de valores culturais e educativos: a pragmática, a epistemológica e a democrática.

Palavras-chave: leitura, literatura trivial, literatura e escola.

19) BOSI, op. cit., p. 340.

20 Ibid., p. 337.

21 Ibid., p. 341. 


\section{RÉSUMÉ}

Cc texte-ci expose les procédés métodologiques envers le choix de la littérature triviale pour l'utilisation à l'école. Il réfléchit sur la constitution textuelle de cette littérature et propose que la lecture de ces textes répétitifs et conservateurs s'attachent a trois philosophies de valeurs culturels et éducationnels: la pragmatique, l'épistémologique et la démocratique.

Mots-clé: lecture, littérature triviale, littérature et école.

\section{REFERÊNCIAS BIBLIOGRÁFICAS}

ATLAS, James. A missão prolixa de escrever sobre a alma. $O$ Estado de S. Paulo, p. D-2, 30 mar. 1997.

BOSI, Alfredo. Dialética da colonização. São Paulo: Companhia das Letras, 1992.

ECO, Umberto. Sobre os espelhos e outros ensaios. 2. ed. Trad. de Beatriz Borges. Rio de Janeiro: Nova Fronteira, 1989.

ENZENSBERGER, Hans Magnus. Mediocridade e loucura. São Paulo: Ática, 1995.

JAUSS, Hans Robert. O texto poético na mudança de horizonte de leitura. In: LIMA, Luiz Costa. Teoria da literatura em suas fontes. 2. ed. Rio de Janeiro: Francisco Alves, 1983. p. 305-358.

KOTHE, Flávio. A narrativa trivial. Brasília: Editora da UnB, 1994.

MAGNANI, Maria do Rosário. Leitura, literatura e escola: sobre a formação do gosto. São Paulo: Martins Fontes, 1989.

SODRÉ, Muniz. Best-seller: a literatura de mercado. São Paulo: Ática, 1985. A verdade seduzida. 2. ed. Rio de Janeiro: Francisco Alves, 1988.

ZILBERMAN, Regina; CADEMARTORI, Ligia. Literatura infantil: autoritarismo e emancipação. São Paulo: Ática, 1982. 